\title{
STUDY ANALYSIS OF ACUTE PANCREATITIS BY CT
}

\author{
Bulabai Karpagam ${ }^{1}$, Hemhnath ${ }^{2}$
}

${ }_{1}^{1}$ Associate Professor, SRM Medical College Hospital and RI, Kancheepuram, Tamil Nadu. ${ }^{2}$ Resident, SRM Medical College Hospital and RI, Kancheepuram, Tamil Nadu.

ABSTRACT: AIM: Study analysis of pancreatitis by computed tomography in terms of morphology of pancreas in acute pancreatitis, complications of pancreatitis and duration of hospital stay by grading the severity of disease using Modified CT severity index.

MATERIAL AND METHOD: This prospective study of 100 patients suspected of pancreatitis was evaluated with multidetector spiral CT scanner, somatom, (Spirit) Siemens at Tertiary care center, for period of one year. The series consists of patients of pancreatitis which were clinically diagnosed and sent directly for CT examination and in the patients in whom abdominal ultrasound examination was suggestive of pancreatitis. Water with iodinated contrast is used as oral contrast so as to distend the stomach and small bowel followed by IV contrast study. All images were viewed at window width-300, window level-40 with a wide and narrow window setting as necessary.

RESULT ANALYSIS: Acute Pancreatitis was more common in males than females with alcohol consumption was the commonest etiological factor in $79.5 \%$. In contrary biliary pathology was the commonest factor in females of $41.6 \%$. Among the 100 cases 41 patients (41\%) developed complications.

CONCLUSION: We had documented a statistically significant correlation between the numeric score obtained with the Modified CT Severity index and the presence of infection, the need for surgery and percutaneous interventions, and the length of the hospital stay. Finally the modified CTSI closely indicates with patient outcome in all study parameters, especially with the length of the hospital stay and the development of organ failure.

KEYWORDS: Acute Pancreatitis, Pancreatitis Complication, CTSI and Morbidity, Acute Pancreatitis and Etiology, Pancreatitis in Female.

HOW TO CITE THIS ARTICLE: Bulabai Karpagam, Hemhnath. "Study Analysis of Acute Pancreatitis by CT". Journal of Evolution of Medical and Dental Sciences 2015; Vol. 4, Issue 92, November 16; Page: 15731-15735, D0I: 10.14260/jemds/2015/2270.

INTRODUCTION: Over the last few years cross sectional imaging, in particular, high resolution bolus contrast enhanced CT has dramatically improved the diagnosis and treatment of acute pancreatitis. The high contrast levels achieved during spiral CT accentuate the difference between normal pancreas and pathology and hence help in lesion localization. The CT severity index, an extension of the CT classification system, attempts to improve the prognostic value of CT in acute pancreatitis. The severity index is a scoring system that combines CT grading and the percentage of necrosis to obtain a number that correlate with risk of developing serious local complications such as abscess or infected necrosis, which in turn correlate with increased incidence of morbidity and risk of death. The modified CT severity index in relation to earlier CT scoring system includes features reflecting organ failure and extrapancreatic complications for predicting course.

This index includes presence or absence of acute fluid collection rather than count of collections, it scores necrosis as absent, minimal $(<30 \%)$, or substantial $(>30 \%)$, and it take into consideration extrapancreatic findings such as pleural fluid, ascitis, extrapancreatic parenchymal abnormalities, vascular complications, or involvement of the gastrointestinal tract. ${ }^{1,2,3}$

Financial or Other, Competing Interest: None.

Submission 24-10-2015, Peer Review 25-10-2015,

Acceptance 05-11-2015, Published 13-11-2015.

Corresponding Author:

Dr. Bulabai Karpaga,

Associate Professor, Department of Physiology,

SRM Medical College Hospital and RI,

Kancheepuram, Tamilnadu, India.

E-mail: karaso1987@yahoo.com

DOI:10.14260/jemds/2015/2270.
This study was undertaken to assess the role of spiral CT in the evaluation of pancreatitis, its complications and severity scoring by using Modified CT severity scoring index which correlated well with duration of hospital stay and the outcome of the patient with management

MATERIALS AND METHOD: CT examination was performed on multidetector CT Somatom spirit; Siemens Medical system, at SRM Medical College and Hospital, kattakangulartur. Nemoto CT pressure injector system was employed for IV contrast material administration.

All patients were kept NBM for minimum of six hours before scan. Water with iodinated contrast is used as oral contrast so as to distend the stomach and small bowel. Approximately $500-800 \mathrm{ml}$ of this was given $30-45 \mathrm{~min}$ prior to the start of scan. CT examination was carried out in supine position. Preliminary scout film followed by $5 \mathrm{~mm}$ thin nonenhanced CT scan was obtained in all cases. Contrast enhanced scan was performed in which included $5 \mathrm{~mm}$ sections from the level of xipisternum to the level of iliac crest were obtained with a scan delay of 40 seconds at contrast injection rate of $3 \mathrm{ml} / \mathrm{sec}$. $100 \mathrm{cc}$ of nonionic contrast i.e. omnipaque $300 \mathrm{mg} \%$ was used with a dose of $1.5 \mathrm{ml} / \mathrm{kg}$ at injection rate of $3 \mathrm{ml} / \mathrm{sec}$. injected via $18 \mathrm{G}$ intravenous catheter into the antecubital vein.

All images were viewed at window width-300, window level- 40 with a wide and narrow window setting as and when deemed necessary. Image matrix of $512 \times 512$ was used. The severity of the pancreatitis for each case was assessed by each observer using the Modified CT severity index.

This index includes simplified evaluation of the presence and number of fluid collections and the extent of pancreatic 
necrosis and presence of extrapancreatic findings, such as pleural fluid, ascites, vascular complications (Venous thrombosis, arterial hemorrhage, or pseudoaneurysm formation), and involvement of the gastrointestinal tract (Inflammation, perforation, or intramural fluid collection). Using this modified index, the severity of pancreatitis for each patient was then categorized as mild ( $0-2$ points), moderate (4-6 points), or severe (8-10 points). The Interobserver agreement for assessing the severity of pancreatitis (Mild, moderate, or severe) with modified CT severity index was expressed for reviewers (Observer 1 and observer 2 ) by means of the exact percentage agreement, along with the kappa statistic, which is used to estimate the proportion of interobserver agreement above that expected by chance. A weighted kappa statistic of $0.41-0.60$ was considered to indicate moderate agreement, $0.61-0.80$ was considered to indicate good agreement, and 0.81-1.00 was considered to indicate excellent agreement.

RESULT ANALYSIS: Prospective study done with sampling using descriptive analysis by SPSS software, not applying test data analysis of total of 100 patients, with Clinically, Biochemically suspected or ultrasonographically detected pancreatitis were subjected to CT abdomen in Spiral CT scanner, Somatom (Spirit)Siemens (Germany) at tertiary care center for period of 1year. Pancreatitis was more common in male than in female (M:F 3.5:1) and commonest age group affected was $3^{\text {rd }}$ to $5^{\text {th }}$ decade. 88 patients were male and 12 patients were female and showed mild increase in incidence in middle age group, between $3^{\text {rd }}$ to $5^{\text {th }}$ decades in both (Table 1 and 2).

In males, Alcohol found to be most common etiological factor for acute pancreatitis (79.5\%) (Table 3). In females, Biliary pathologies are found to be the most common etiological factor (41.6\%). Acute fluid collection was both intrapancreatic and extrapancreatic like in lesser sac, anterior pararenal space or subperitoneal space. 18 patients had single fluid collection while 21 patients had two or more fluid collections.

Most common site for peripancreatic inflammatory change was anterior pararenal space. Table 4 denotes complications of acute pancreatitis, where Pancreatic necrosis was found in 14\%, which was infected in 2(14.3\%) and Pancreatic abscess found in $\%$ patients. Vascular and hemorrhagic complications were found in $1(1 \%)$ cases. Spleenic vein thrombosis in 1 patients (Graph1).

Using the Modified CT severity index, we graded the severity of the acute pancreatitis as mild in 50 , moderate in 31 , and severe in 19 of the 100 patients. Interobserver agreement on these observations ranged from $70 \%$ to $79 \%$ (Mean, 74\%).

The kappa statistic for observers ranged from 0.51 to 0.66 , indicating moderate to good agreement (A weighted kappa statistic of $0.41-0.60$ was considered to indicate moderate agreement, $0.61-0.80$ was considered to indicate good agreement, and 0.81-1.00 was considered to indicate excellent agreement). In none of the cases was the severity of the pancreatitis scored differently by both the observers.

DISCUSSION: A total of 100 patients were diagnosed having Acute Pancreatitis using spiral CT Pancreatic parenchymal images were obtained with a delay of 40 seconds, $3.5 \mathrm{ml} / \mathrm{sec}$ which gave a maximum pancreatic parenchymal enhancement of $85 \mathrm{HU}$. This is correlated with the study by Tonsok Kim et al Tublin et al.4,5 Majority of male patients (79\%), who were diagnosed having pancreatitis, gave history of alcohol abuse as noted in previous studies by Brooke Jeffery et al. ${ }^{6}$ (Found 24 out of 32 patients) and by Gaston Mendez et al. ${ }^{7}$ Peak age incidence of acute pancreatitis was noted in 30-50 yrs. of age range in our study and showed that (78.0\%) of acute pancreatitis had diffuse enlargement of gland compared with previous study.6,7 22 of 100 patients (22.0\%) suggestive of edematous pancreatitis with mean age of 40years. In this study, peripancreatic inflammatory changes were noted in 74 patients (74.0\%) with involvement of anterior pararenal space in 43 patients, lesser sac in 19 patients and mesentery/mesocolon in 12 patients compared with study by Hill et al. ${ }^{8} 11 \%$ peripancreatic inflammatory changes in patients of acute edematous pancreatitis and $89 \%$ peripancreatic inflammatory changes in patients of necrotizing pancreatitis.

This difference could be accounted for by the better differentiation of the inflammed pancreas from the surrounding peripancreatic inflammatory changes due to rapid spiral scanning in peak parenchymal enhancement phase and lack of respiratory misregistration artifact. Pancreatic necrosis defined as areas of low attenuation i.e. less than $<30 \mathrm{HU}$ enhancement on CECT was noted in 14 patients $(14.0 \%)$ of which nine patients had less than $30 \%, 5$ patients had more than $30 \%$ Among 14 patients with Necrotizing Pancreatitis, Necrosis was sterile in 12 patients (12.0\%) (09 with $<30 \%$ of necrosis and 3 with $>30 \%$ necrosis). Infected in 2 patients (14.3\%) cases among which all of them have $>30 \%$ necrosis. Balthazar EJ etal. ${ }^{3}$ found similar results with total necrosis being $20.4 \%$ and most patients with higher grade pancreatitis which were comparable to the present study. In present study one patient had spleenic vein thrombosis. Despite the fact that the CT severity index had been successfully used to predict overall morbidity and mortality in patients with acute pancreatitis, recent literature has revealed the limitations of this currently accepted CT severity index. 9,10 In light of these limitations, we hypothesized that a simplified CT severity index that incorporated features reflecting organ failure and extrapancreatic complications would be useful for predicting outcomes more accurately.

Using the modified CT severity index, we graded severity of the acute pancreatitis as mild, moderate or severe with CT scans (Table 5). The kappa statistic for each pair of observers ranged from 0.52 to 0.65 , indicating moderate to good agreement (A weighted kappa statistic of $0.41-0.60$ was considered to indicate moderate agreement, $0.61-0.80$ was considered to indicate good agreement, and $0.81-1.00$ was considered to indicate excellent agreement). In none of the cases was the severity of the pancreatitis scored differently by observers. Correlation between the index and the length of the hospital stay, we found a statistically significant correlation between the modified index and the length of hospital stay $(p=0.001)$ for all severity groups. Significant correlation between the need for surgical or percutaneous interventions and the severity of pancreatitis was seen with the modified CT severity index $(p=0.0001)$. Similarly, the presence of infection 
was correlated with higher scores modified CT severity index $(\mathrm{p}=0.0001)$. Mean length of hospital stay in terms of days was 5 days for Mild Pancreatitis, 11 days for Moderate Pancreatitis and 15 days for severe Pancreatitis. The length of the hospital stay ranged from 0 to 35 days (Mean, 7.2 days). Mean length of hospital stay in terms of days was 5 days for Mild Pancreatitis, 11 days for Moderate Pancreatitis and 15 days for severe Pancreatitis (Graph 2). The length of hospital stay for grade of Pancreatitis was found to be higher in comparison to the previous study by Koenraad.11 Significant correlation between the need for surgical or percutaneous interventions and the severity of pancreatitis was seen with the modified CT severity index $(p=0.0001)$. Finally, a significant correlation $(p=0.00002)$ was seen between the modified severity index score and the development of organ failure.

CONCLUSION: Helical CT evaluation of Pancreas if scanned during the peak parenchymal enhancement phase, helps in better morphological characterization of acute pancreatitis and the complications. We had documented a statistically significant correlation between the numeric score obtained with the Modified CT Severity index and the presence of infection, the need for surgery and percutaneous interventions, and the length of the hospital stay. Finally the modified CTSI closely indicates with patient outcome in all study parameters, especially with the length of the hospital stay and the development of organ failure.

\section{REFERENCES:}

1. Balthazar Emil J, Robinson David L, Megibow Alec J, Ranson John HC: Value of CT in Establishing Prognosis; Radiology 1990; 74:331-336.

2. Balthazar Emil J: Pancreatitis; In Textbook of gastrointestinal Radiology Vol.2, Gore Richard M, Levine

Marc S, Laufer Igor; W B Saunders Company; 1994; Pg 2132-2134.

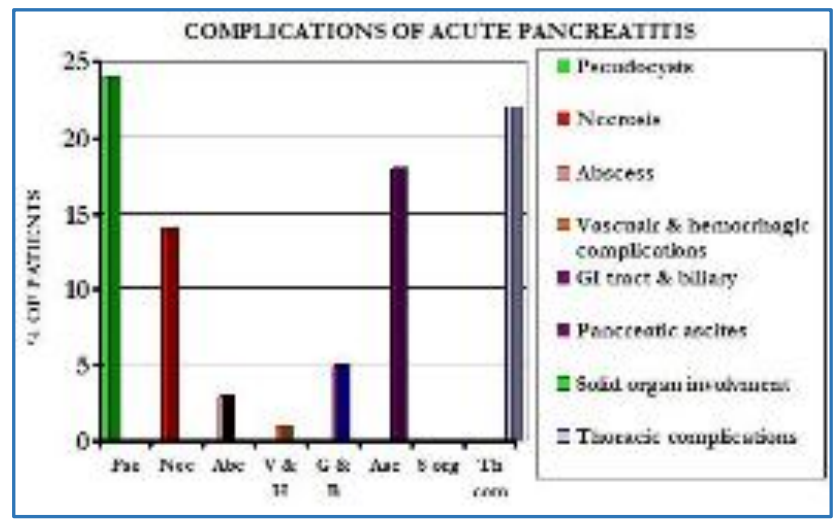

3. Balthazar EJ: Acute Pancreatitis: Assessment of Severity with Clinical and CT Evaluation; Radiology 2002; 223:603-613.RSNA. (3 to 7).

4. Tonsok Kim, Takamichi Murakami, Satoru Takahashi, Atsuya Okada, Masatoshi Hori, Yoshifumi Narumi, and Hironobu Nakamura, Torres WE, Clements JL, Sones PJ, Knopf DR: Gas in the pancreatic bed without abscess; AJR 1981; 137: 1131-1133.

5. Tublin Mitchell E, Franklin N Tessler: Effect of Injection Rate of Contrast Medium on Pancreatic and Hepatic Helical CT Radiology. 1999; 210: 97-101.

6. Brooke Jeffery R, Federle Michael P, Jeffery Brooke R, Cello John P: Early Computed Tomographic Scanning in Acute Severe Pancreatitis; Surgery, Gynecology \& Obstetrics; February 1982, Volume 154.

7. Mendez Gaston, Jr., Isikoff Michael B, Hill Michael C: CT of Acute Pancreatitis: Interim Assessment; AJR. 135:463-469, September 1980.

8. Hill Michael C. Barkin Jamie. IsikotT Michael B, Silverstein William, Kaiser Martin: Acute Pancreatits: Clinical vs. CT Findings; AJR 139: 263 - 269, August 1982.

9. Mortele KJ, Mergo P, Taylor H, Ernst M, Ros PR. Renal and perirenal space involvement in acute pancreatitis: stateof-the-art spiral CT findings. Abdom Imaging 2000;25:272-278.

10. Wiesner W, Studler U, Kocher T, Degen L, Buitrago-Tellez $\mathrm{CH}$ etal Colonic involvement in non-necrotizing acute pancreatitis: correlation of CT findings with the clinical courseof affected patients. Eur Radiol 2003;13:897-902.

11. Koenraad J. Mortele, Walter Wiesner, Lisa Intriere, Shridhar Shankar, Kelly H. Zou1: A Modified CT Severity Index for Evaluating Acute Pancreatitis: Improved Correlation with Patient Outcome: AJR November 2004:183: 1261-1265.

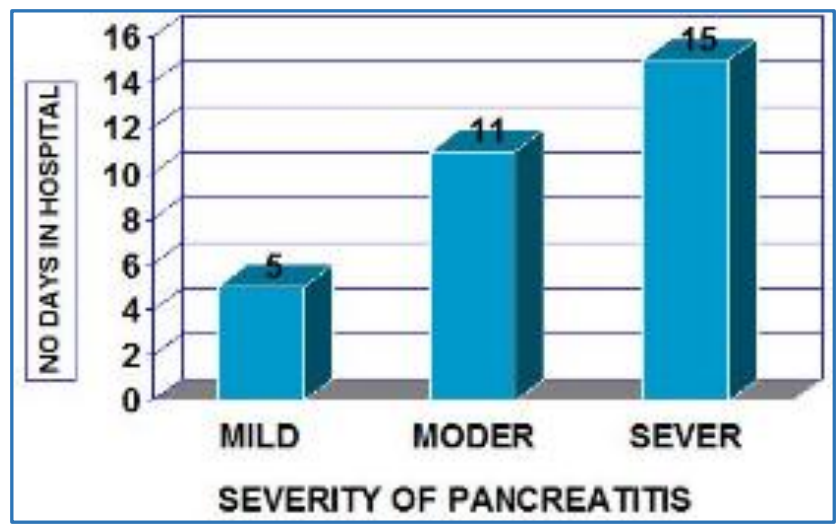




\begin{tabular}{|c|c|c|c|c|}
\hline \multicolumn{5}{|c|}{$\begin{array}{l}\text { Table No.1 } \\
\text { AGE AND GENDER WISE DISTRIBUTION OF ACUTE PANCREATITIS } \\
\text { DIAGNOSED ON CT }(n=100)\end{array}$} \\
\hline AGE (YRS) & MALE & $\%$ & FEMALE & $\%$ \\
\hline $0-10$ & 0 & 0 & 0 & 0 \\
\hline $10-20$ & 0 & 0 & 1 & 8.3 \\
\hline $21-30$ & 20 & 22.7 & 1 & 8.3 \\
\hline $31-40$ & 31 & 35.2 & 1 & 8.3 \\
\hline $41-50$ & 24 & 27.3 & 3 & 25 \\
\hline $51-60$ & 9 & 10.2 & 3 & 25 \\
\hline $61-70$ & 5 & 5.7 & 3 & 25 \\
\hline$>71$ & 0 & 0 & 0 & 0 \\
\hline Total & 88 & & 12 & \\
\hline
\end{tabular}

Table No.2

AGE AND GENDER WISE DISTRIBUTION OF ACUTE PANCREATITIS $(n=100)$

\begin{tabular}{|c|c|c|}
\hline AGE (YRS) & MALE & FEMALE \\
\hline $0-10$ & 0 & 0 \\
\hline $11-20$ & 0 & 1 \\
\hline $21-30$ & 20 & 1 \\
\hline $31-40$ & 31 & 3 \\
\hline $41-50$ & 23 & 3 \\
\hline $51-60$ & 9 & 3 \\
\hline $61-70$ & 3 & 0 \\
\hline$>71$ & 0 & 12 \\
\hline Total & 88 & 1 \\
\hline
\end{tabular}




\begin{tabular}{|c|c|c|}
\hline \multicolumn{3}{|c|}{ Table No.3 } \\
\hline MOST COMMON ETIOLOGIES ACCORDING TO GENDER ( $\mathbf{n = 1 0 0 )}$ \\
\hline ETIOLOGY & NO OF MALE (\%) & NO OF FEMALE (\%) \\
\hline ALCOHOL & $70(79.6)$ & 0 \\
\hline BILIARY & $9(10.2)$ & $5(41.7)$ \\
\hline $\begin{array}{c}\text { OTHERS } \\
\text { (Metabolic disorders, } \\
\text { Autoimmune, } \\
\text { Infectious, } \\
\text { and others) }\end{array}$ & $9(10.2)$ & $7(58.3)$ \\
\hline
\end{tabular}

\begin{tabular}{|c|c|c|c|}
\hline \multicolumn{2}{|l|}{ Complications } & NO. & $\%$ \\
\hline \multicolumn{2}{|l|}{ Pseudocyst } & 24 & 24 \\
\hline \multirow{2}{*}{ Necrosis } & $<30 \%$ & 9 & 9 \\
\hline & $>30 \%$ & 5 & 5 \\
\hline Presence of gas/abscess & & 3 & 3 \\
\hline GI tract \& biliary involvement & & 5 & 5 \\
\hline $\begin{array}{l}\text { Solid organ involvement } \\
\text { (spleen, kidney and liver) }\end{array}$ & & 0 & 0 \\
\hline $\begin{array}{l}\text { Thoracic complications (effusion, } \\
\text { mediastinal pseudocyst and etc) }\end{array}$ & & 22 & 22 \\
\hline $\begin{array}{l}\text { Vascular and hemorrhagic } \\
\text { complications }\end{array}$ & & 1 & 1 \\
\hline Ascites & & 18 & 18 \\
\hline
\end{tabular}

\begin{tabular}{|c|c|}
\hline \multicolumn{2}{|c|}{$\begin{array}{l}\text { Table No.5 } \\
\text { DISTRIBUTION OF PATIENTS OF ACUTE PANCREATITIS } \\
\text { ACCORDING TO MODIFIED CT SEVERITY INDEX } n=100\end{array}$} \\
\hline SEVERITY CATEGORISATION & NO. OF PATIENTS $(\%)$ \\
\hline MILD & 50 \\
\hline MODERATE & 31 \\
\hline SEVERE & 19 \\
\hline
\end{tabular}

